Journal of Advanced Research in Fluid Mechanics and Thermal Sciences

\title{
Innovative Hydrocarbon Sensor for Real Drive Emission Testing: Optimization of the Gas Inlet
}

\author{
Nurain Rozy ${ }^{1,2}$, Norazlianie Sazali ${ }^{1,}{ }^{*}$, Saiful Anwar Che Ghani ${ }^{1}$, Maurice Kettner ${ }^{2}$ \\ Faculty of Mechanical \& Automotive Engineering Technology, Universiti Malaysia Pahang, 26600 Pekan, Pahang, Malaysia \\ Hochschule Karlsruhe-Technik und Wirtschaft, Karlsruhe University of Applied Sciences, 76012 Karlsruhe, Germany
}

\section{ARTICLE INFO}

Article history:

Received 2 September 2020

Received in revised form 25 April 2021

Accepted 1 May 2021

Available online 24 June 2021

\section{Keywords:}

Hydrocarbon sensor; Numerical analysis;

Inlet Optimization; AVL Fire

\section{ABSTRACT}

\begin{abstract}
Hydrocarbon emission is very bad for human health. Many efforts were made to reduce the pollution of hydrocarbon sensor especially in vehicle. For that, the development of hydrocarbon sensor for emission testing on the road is one of the great approaches to compare the results from laboratory test and in real driving test. This work focused on numerical investigation and optimization of hydrocarbon sensor prototype that is using glow plug as the heat source. Heat is important in facilitating ionization process for ion current measurement. Therefore, numerical optimization of inlet design and simulation using AVL Fire was done and reported in the following work to obtain the maximized performance of hydrocarbon sensor. We found that the optimum conditions for heating gas inside the chamber is when the inlet create a swirl flow and at low velocity.
\end{abstract}

\section{Introduction}

Starting September 2017, new cars in Europe needs to adopt the new procedure called Worldwide Harmonized Light Duty Test Procedure (WLTP) for light-duty vehicles [1]. Currently, both WLTP and New European Driving Cycle (NDEC) are used in European countries. The cycle test includes the drive test which is WLTP-Phases Low-Medium-High-Medium. The test takes place on real roads and known also as Real Driving Emission (RDE) test that compliments lab tests. This is done by measuring pollutant emissions of the vehicles on the road. Real driving emissions (RDE) tests will measure the pollutants, such as NOx, emitted by cars while driving on the road. RDE will not replace laboratory tests, such as the current NEDC and the future WLTP but it will be additional to them. For RDE tests, a device called Portable Emission Measuring System (PEMS) will be placed in the vehicle [2]. This device will provide a complete real-time monitoring of the exhaust species emitted. It should be noted that there are no established standard PEMS equipment for the test. Hence, different PEMS will deliver a slightly different result from the other PEMS device [3].

\footnotetext{
* Corresponding author.

E-mail address: azlianie@ump.edu.my

https://doi.org/10.37934/arfmts.84.1.110
} 
The major concern of the hydrocarbon emission from the exhaust gas is because hydrocarbon is one of the three greenhouse gas emissions $\left(\mathrm{CO}_{2}, \mathrm{CH}_{4}\right.$ and $\left.\mathrm{N}_{2} \mathrm{O}\right)$ [4]. Methane $\left(\mathrm{CH}_{4}\right)$ and other unburned hydrocarbons which are the by-product of the combustion contributed about $10 \%$ of the greenhouse gas emission while Carbon Dioxide contribute about $82 \%$, Nitrous Oxide is about $6 \%$ and Fluorinated Gas is about 3\% [5]. For the new Euro 6 emission standards that are introduced in September 2015, aiming to reduce the level of harmful exhaust from both petrol and diesel. The Euro 6 emissions limit for Hydrocarbon is $0.10 \mathrm{~g} / \mathrm{km}$ and for diesel is $0.17 \mathrm{~g} / \mathrm{km}$ [6]. The sensor to measure hydrocarbon emission in real driving on the road using PEMS currently is using the estimated mass emission collected from data from OBD port in the vehicle. This is however not the actual emission data from the vehicle in the real-life driving. In laboratory, the gas chromatograph Flame Ionization Detector (FID) device is the common technique to measure level of composition of hydrocarbon in exhaust gas coming from the vehicle [7]. However, this technique is not reliable for RDE because the flame inside the FID needs hydrogen gas. As we know, hydrogen gas could serve extreme consequence for example probability to explode in case of accident. This can cause harm to the driver, passenger, and vehicle.

For the new hydrocarbon sensor prototype, the heating element is changed to glow plug. Ceramic glow plug can operate in the maximum temperature of $1300^{\circ} \mathrm{C}$ [8]. While the temperature of the hydrogen flame in the FID is around $2800^{\circ} \mathrm{C}$ [9]. With the differences in the temperature, it is a challenge to optimize and enhanced the area where the heating gas process in the new hydrocarbon chamber sensor. For this purpose, simulation study is the best tool to use. With the help of simulation studies, the temperature distribution and the behaviour of the gas acting in different cases or with different parameter can be studied more thoroughly. Since there are no specific technologies is mandated to meet or measure the standards, the inventions of hydrocarbon sensor for real-driving emission have its demands in the field of vehicle emission testing. In addition, this prototype of the hydrocarbon sensor for emission tests has a good future for it to be further developed. The aim of the project is to analyse and optimize the HC sensor. This includes performing CFD analysis using commercial software AVL Fire at the region where the heating process of the gas occur. This region is important because it is the place where ionization of the gas happen.

\subsection{Flame lonization Detector (FID)}

In emission testing, measurement of the composition of hydrocarbon in exhaust gas is measured using Flame Ionization Device (FID). It is one of the gas chromatography techniques that is used for the detection of the composition of hydrocarbon in the exhaust gas [10]. The process inside FID can simply be explained in Figure 1 which starts with sample gas being introduced inside the column capillary, heated up in the column oven and goes to the FID chamber which is then burned by the hydrogen flame together. From the burning process, the hydrocarbon molecule will ionize, and FID signal is given by the measurement of the ion current at the detector [11]. The function detector in the FID device is to detect ions produced during the combustion of the gas in the hydrogen flame. Usually, the ions generated is proportionally to the amount of organic compound present in the sample gas stream that comes from the column. With difference of electric signal occur when the electron flow inside the circuit that decrease the resistance inside the circuit, the ion current can be measured. The current measured are usually very small and needs to be measured using Picoammeter which is then is amplified to a proper voltage and is feed into an integrator. FID have the capability to read ion current with range at least from nanometer $\left(10^{-9}\right)$ to milimeter $\left(10^{-3}\right)$. The final data displayed will be shown as the peak. Each peak indicates how many components are there in the gas mixtures. On the $\mathrm{x}$-axis displayed is usually the amount of time taken for the analyte to 
pass through the column and reach the FID detector. However, the drawbacks of this technique are that it consumes the sample of the gas fed and the condensation problem which formed in the flame.

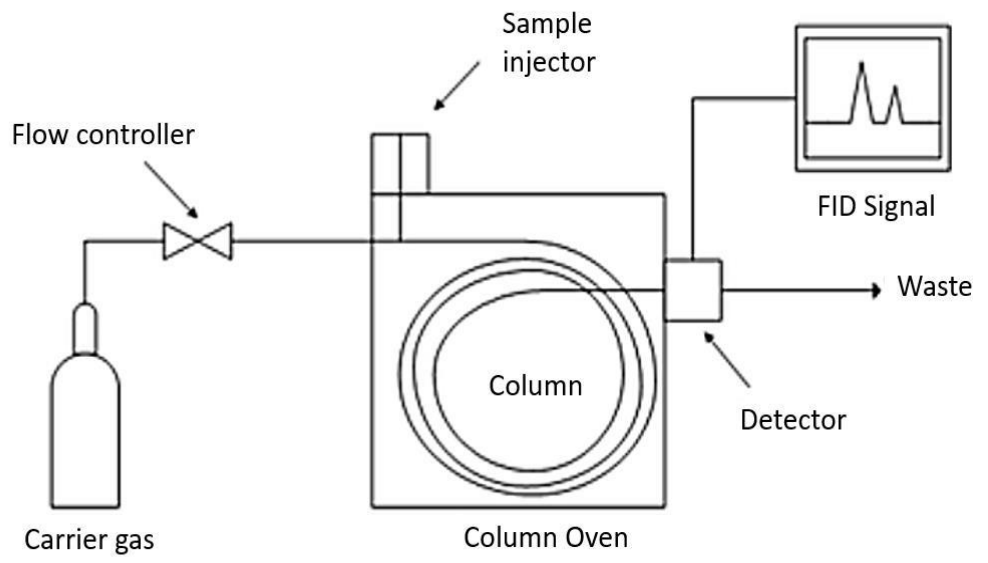

Fig. 1. A simple chromatograph diagram

\section{Experimental Setup and Methods}

\subsection{Physical Domain to Computational Domain Conversion}

Figure 2 below shows the 2D physical domain of the hydrocarbon sensor chamber. In order to perform CFD simulation, the physical domain must be converted into computational domain. Our main focus is at the glow plug area where the ionization process occurs.

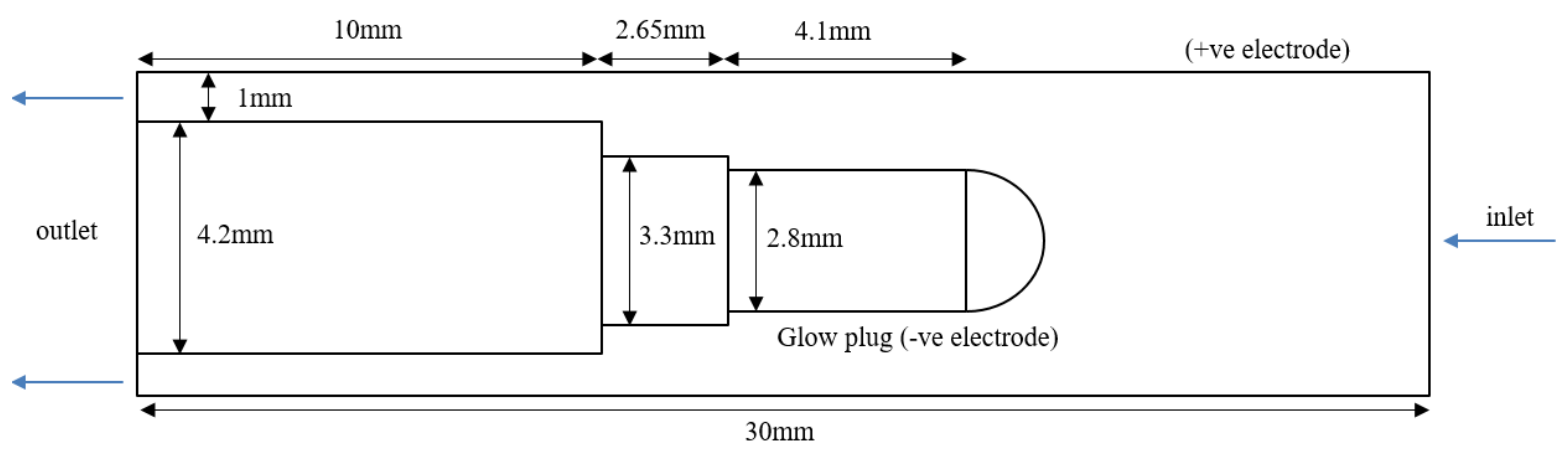

Fig. 2. 2D diagram for hydrocarbon sensor chamber used in this study with its dimension

Experimental set up is as shown in Figure 3. The tip of the glow plug temperature is measured using the pyrometer. Here the glow plug is heated up inside the chamber with condition of no air flow. From the measurement, the temperature of the glow plug is $985.279^{\circ} \mathrm{C}$. In mesh independency test, mesh size depends on the refinement value applied to the model. By increasing the value of mesh, the number of cells increase. Thus, increasing the accuracy of simulation results obtained. Without refinement, the value of glow plug temperature obtained is far from the measured value from the experiment. A comparison between simulation and experimental glow plug temperature are shown in Figure 4 below. 


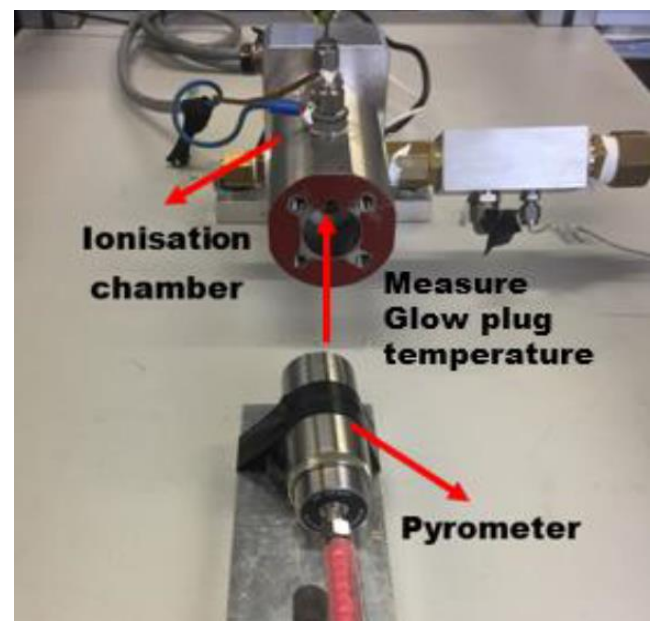

Fig. 3. Experimental set up for glow plug temperature measurement

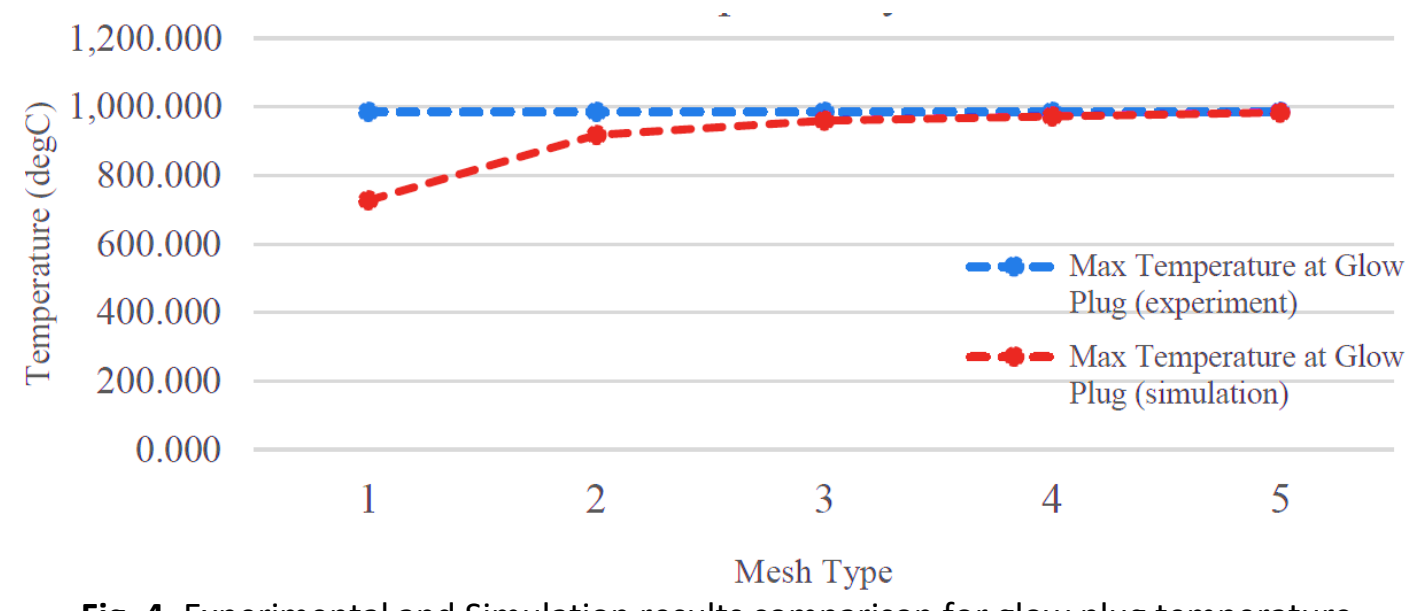

Fig. 4. Experimental and Simulation results comparison for glow plug temperature

\subsection{Simulation Model}

\subsubsection{Study of flow compressibility and fluid properties}

Type of fluid used for simulation study was propane gas due its simplicity. In the experiment the gas used is a Nitrogen-Propane-Mixture. Properties of propane gas are outlined in Table 1. The numerical scheme that we use is SIMPLE (Semi-Implicit-Method for Pressure Linked Equations).

Table 1

Propane gas properties

\begin{tabular}{ll}
\hline Properties & Value \\
\hline Gas Constant & $188.56 \mathrm{~J} / \mathrm{kgK}$ \\
Specific heat & $1630 \mathrm{~J} / \mathrm{kgK}$ \\
Dynamic viscosity & $7.4 \times 10^{-6} \mathrm{Ns} / \mathrm{m}^{2}$ \\
Thermal conductivity & $1.7 \mathrm{~mW} / \mathrm{mK}$ \\
Reference pressure & $10000 \mathrm{~Pa}$ \\
Reference temperature & $293.15 \mathrm{~K}$ \\
Reference density & $1.809 \mathrm{~kg} / \mathrm{m}^{3}$ \\
\hline
\end{tabular}

Two studies are made to find out the effect of different flow compressibility mode. The purpose of studying these two types of compressible and incompressible flow is to find out the effect of 
choosing between these two types of flow. The compressibility for the fluid used in this simulation depends on the velocity of the fluid. Which is the Mach number. For incompressible the Mach number must be smaller than 0.3. Formula for Mach number are as below

$M=\frac{v}{c}$

where, $v$ is the speed or velocity of an object and $c$ is the speed or velocity of sound. For compressible flow, the fluid density varies with its pressure. In this simulation, we are dealing with the heating process of gas, thus the density of the gas decrease as it is heated up by the glow plug wall. Therefore, it increases the temperature inside the chamber. The relationship between the pressure, temperature and the density can be seen in the mathematical formula below

$\rho=\frac{P}{R \cdot T}$

where, $\rho$ is the density of gas $\left(\mathrm{kg} / \mathrm{m}^{3}\right), P$ is the air pressure $(\mathrm{Pa}), R$ is the specific gas constant $(\mathrm{J} / \mathrm{kg} . \mathrm{K})$ and $T$ is the temperature (K). For both flows, the value of mass flow obtained from simulation were $1.366 \times 10^{-5} \mathrm{~kg} / \mathrm{s}$. However, in compressible setting, the temperature contour was much more spread and higher than using the incompressible flow. These shows that the gas around the glow plug is heated up thus change the density of the gas. Meanwhile for the velocity settings, compressible flow produced higher gas velocity compared to the incompressible flow. This is due to gas in compressible setting heated up and causing the kinetic energy of the gas to increase and therefore increase the speed of the gas. The maximum velocity for incompressible gas is $0.72265 \mathrm{~m} / \mathrm{s}$ and $5.4697 \mathrm{~m} / \mathrm{s}$ for compressible gas. The total mass for compressible flow is not consistent until the end of iterations. But for incompressible flow, the total mass is consistent throughout the iterations process. Total volume is the same for both types of case. For mean temperature, incompressible flow shows a smaller number of iterations while for compressible flow, a greater number of iterations is needed. Initial conditions value for initial pressure, temperature and velocity in the simulation were 100000 $\mathrm{Pa}, 293.15 \mathrm{~K}$ and $0 \mathrm{~m} / \mathrm{s}$, respectively. The initialization mode is uniform initialization.

\subsubsection{Numerical calculation of ions current}

Numerical calculation for ions current measurement was referred from Saitzkoff-Reinmann derivation model based on their study on ionization equilibrium analysis of the spark plug as an ionization sensor [12]. The process happens inside of the new hydrocarbon sensor prototype can be visualise as in Figure 5. The exhaust gas will flow inside the hydrocarbon sensor and then it is heated by the glow plug with temperature around 1000K. Temperature of the glow plug can be controlled by controlling the amount of voltage given to the glow plug. Here, the voltage for the glow plug is $6 \mathrm{~V}$ and the electrode is around 200V. To calculate the electric current that comes from the heating of the gas, we need to determine the number of free electrons in the gas and their velocity. In this hydrocarbon sensor we assume that the sources of the ions are mainly contributed by thermal ionization and not chemical ionization. There are two factors that needed to be modelled are the ionization ratio and the drift velocity of the electrons. Ionization ratio can be obtained from Saha's equation and the electron drift velocity can be obtained from the basic of gas kinetic theory [13-15]. To further simplify the derivation, we need to simplify the geometry of the volume where ionization process happens. 


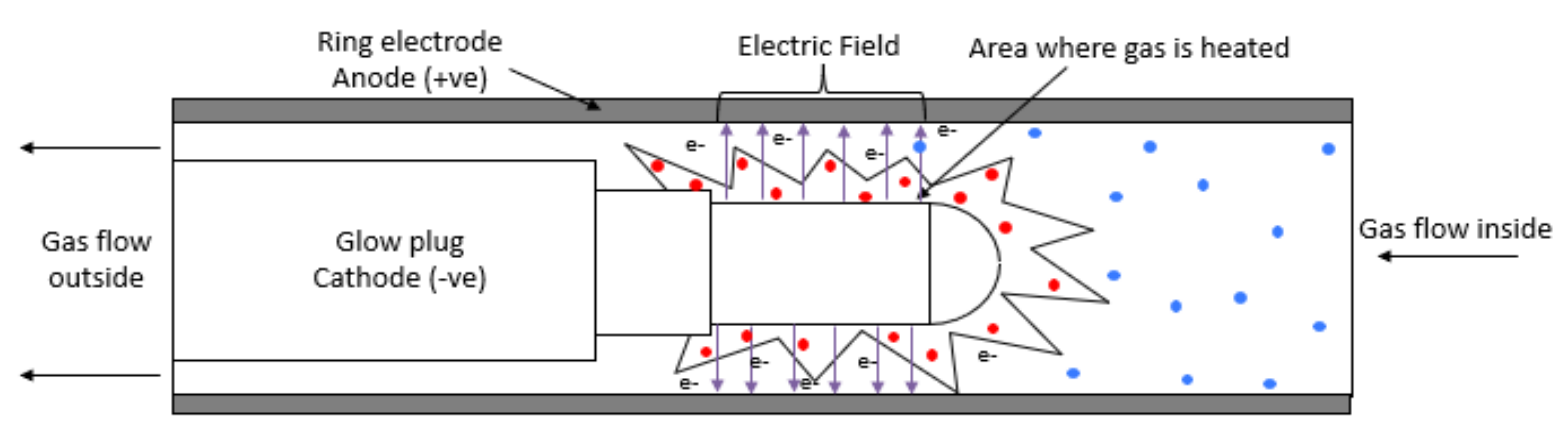

Fig. 5. Illustration of ionization process inside hydrocarbon sensor

We want to evaluate the current that is given by Propane gas, $\mathrm{C}_{3} \mathrm{H}_{8}$. The ionization energy of propane gas is $10.94 \mathrm{eV}$. In this study, assumption was made that the gas is not mixed with other gases. To find the expression for the current we must investigate the drift velocity and the mobility of the electrons. The formula for the drift velocity is

$v_{d}=\mu X$

where, $v_{d}$ is electron drift velocity $(\mathrm{m} / \mathrm{s}), \mu$ is the mobility of electron $\left(\mathrm{m}^{2} / \mathrm{Vs}\right), \mathrm{X}$ is the electric field $(\mathrm{V} / \mathrm{m})$. In the hydrocarbon chamber, we let the hydrocarbon gas flow inside the chamber which then is heated up by the glow plug. With electric field generated between the electrode ring (anode) and the glow plug (cathode), there are some interactions happen between the electrons, ions and the neutral atoms or molecule such as elastic collision, inelastic collision, excitation, ionization and recombination. The derivation of the equation for ion current comes from the Saitzkoff-Reinmann derivation model which is used to analyse ionization equilibrium of the spark plug as ionization sensor.

$I=\frac{U}{d} e^{2} \sqrt{2 \frac{\left(\frac{2 \pi m_{e} k T}{h^{2}}\right)^{3 / 2} \frac{B_{i}}{B_{o}} \exp \left[-\frac{E_{i}}{k T}\right]}{n_{t o t}}\left(\pi r^{2}\right)\left(\frac{1}{\sigma m_{e} \sqrt{\frac{8 k T}{\pi m_{e}}}}\right)} \frac{1}{\varphi_{s}}$

From this formula we can see the relationship between the current, $I$ and with parameter such as temperature, $T$ and density of particles, $n_{\text {tot }}$ by assuming that the species fraction, $\varphi_{s}$ is 1 based on our assumption at the beginning that the gas is single species and is not mixed with other different gas species. Here we can also see the linear relationship between the current and the electric field given by $U / d(\mathrm{~V} / \mathrm{m})$. Increasing supplied voltage or decreasing the distance between electrode can improve ion current measurement. The values that we use in this calculation is as in Table 2.

Table 2

Parameter values used in calculation

\begin{tabular}{ll}
\hline Parameter & Value \\
\hline Glow plug supplied voltage, $\mathrm{U}$ & $6 \mathrm{~V}$ \\
Distance between cathode and anode, $\mathrm{r}$ & $1.7 \mathrm{~mm}$ \\
Distance travelled by the electron, $\mathrm{d}$ & $1 \mathrm{~mm}$ \\
Cross section area where the electron passing through, $\sigma$ & $2.404 \times 10^{-5} \mathrm{~m}^{2}$ \\
Internal partition function, $\mathrm{Bi}=\mathrm{Bo}$ & 1 \\
Density, $\rho$ & $1000 \mathrm{ppm}$ \\
Pressure, $\mathrm{p}$ & $100000 \mathrm{~Pa}$ \\
\hline
\end{tabular}




\section{Results and Discussion}

\subsection{Flow Compressibility}

The compressibility for the fluid used in this simulation depends on the velocity of the fluid. From our simulation, we compared both temperature and velocity graph at two types of flow; compressible and incompressible flow. By using compressible setting, the temperature contour was much more spread and higher than using the incompressible flow (Refer Figure 6). These shows that the gas around the glow plug $(x=0.015 \mathrm{~m})$ is heated up thus change the density of the gas. Next, velocity result for compressible flow shows much more higher gas velocity compared to the incompressible flow (based on Figure 7). The reason behind this result is because the gas in compressible setting was heated up, causing the kinetic energy of the gas to increase and therefore, increase the speed of the gas. The maximum velocity obtained for incompressible gas was 0.72265 $\mathrm{m} / \mathrm{s}$ and $5.4697 \mathrm{~m} / \mathrm{s}$ for compressible gas.
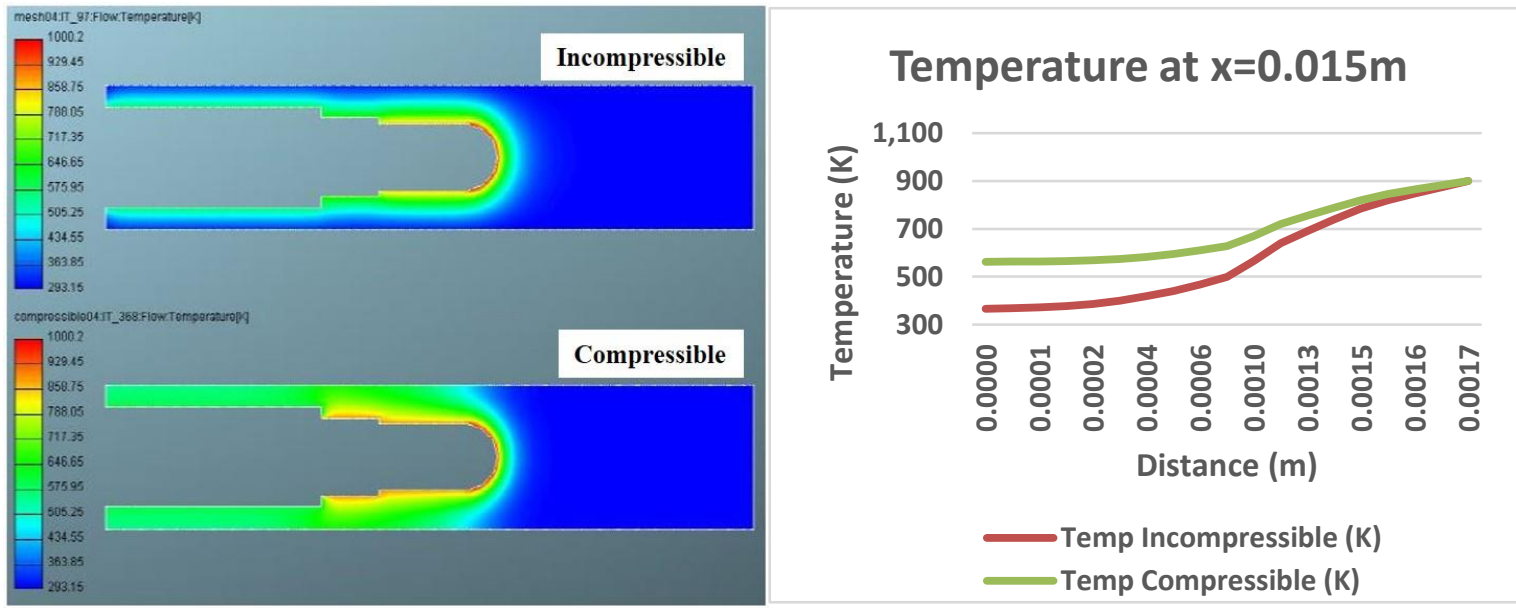

Fig. 6. Temperature contour (left) and Temperature graph (right) for incompressible and compressible flow
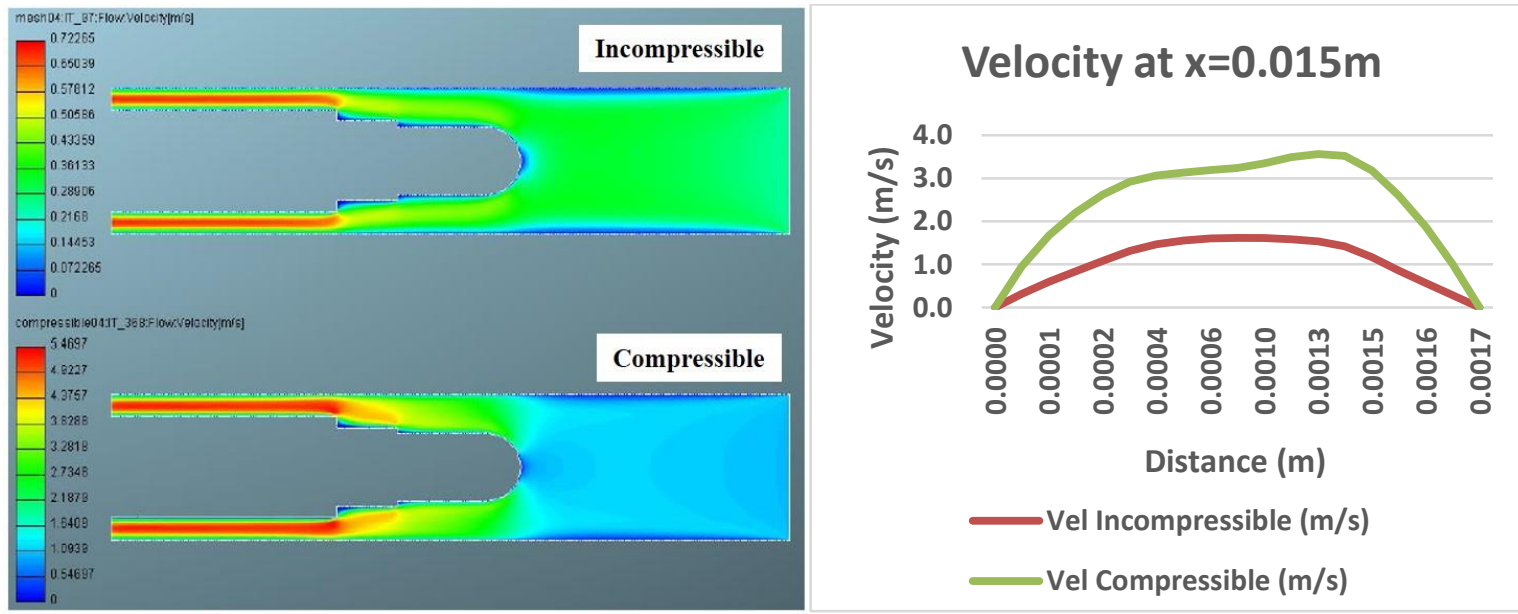

Fig. 7. Velocity contour (left) and Velocity graph (right) for incompressible and compressible flow

\section{2 lon Current Measurement}

Parameter values listed in Table 2 were insert in Eq. (4) and the current was calculated at different temperature. Three temperatures were chosen which are $800 \mathrm{~K}, 1000 \mathrm{~K}$ and $1200 \mathrm{~K}$. Calculated result are tabulated in Figure 8 below. 


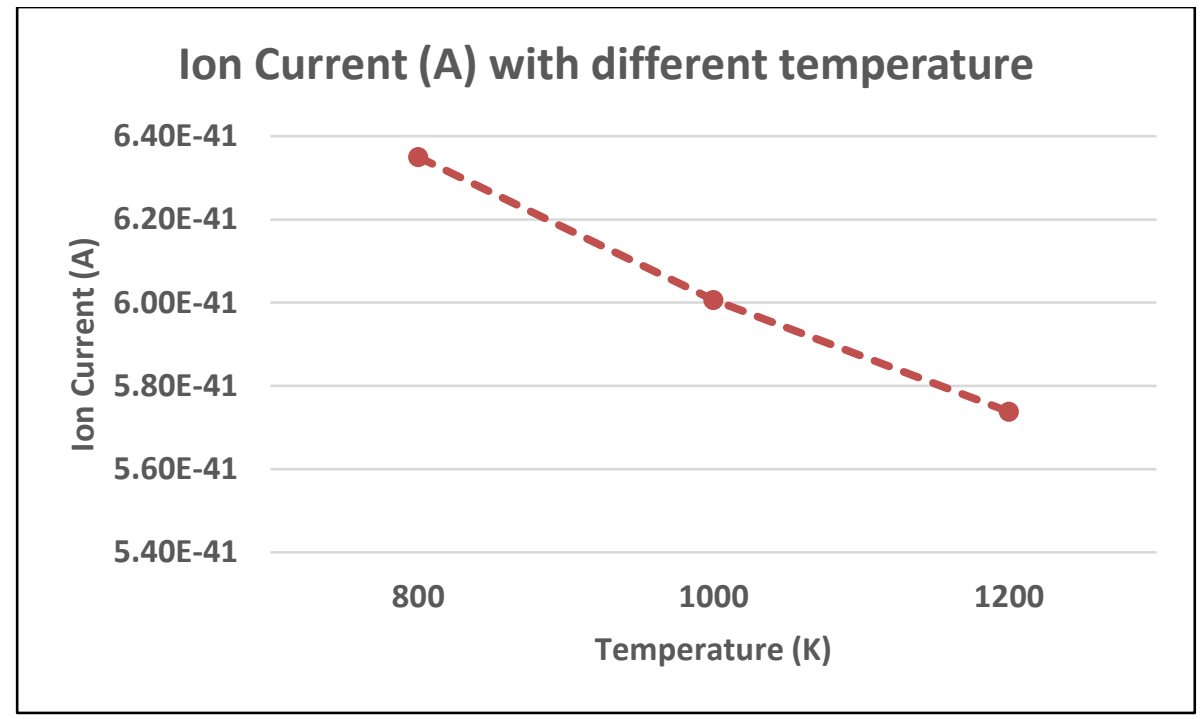

Fig. 8. Ion current measurement at different temperature

For the calculated ion current at different temperature, ion current is decreasing as the temperature increase. Our calculated result from the formula derivation is too small compared to the achieved value from the past paper [5]. It is due to different parameter that was used in our case and lack of understanding of the physics phenomena that happen inside the hydrocarbon chamber.

\section{Optimization Study}

Inlet position were investigated to enhance the flow of the gas inside the hydrocarbon chamber. Four types of inlet position designs as in Figure 9 were simulated and compared in terms of velocity and temperature distribution at the glow plug.

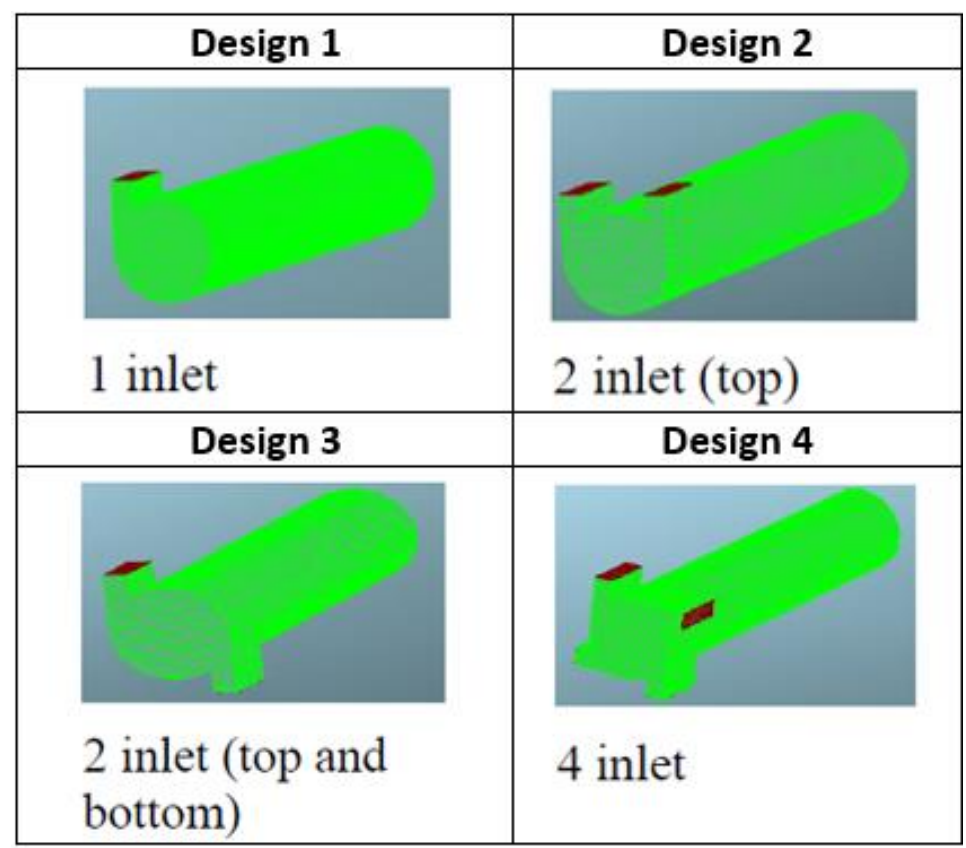

Fig. 9. Different designs for inlet position optimization

Based on Figure 10, Design 2 shows the highest temperature distribution around the glow plug. The reason is because the position of the both inlet with the same direction at the top will causes the 
gas flow inside meet each other at the beginning and therefore create more inconsistent flow and causes the velocity of the gas become much slower thus improve the heating process. Compared with other three designs, Design 2 does not show a swirl flow inside the chamber. But this also means that the gas does not flow around the glow plug but instead it flows direct to the tip of the glow plug. Furthermore, this will make the more gas will flow to the tip of the glow plug which is the hottest area and thus more gas is heated up and make the temperature inside the chamber increase. For Design 1, 3 and 4 which has swirl flow around the glow plug shows almost the same temperature distribution.

\section{Design01}
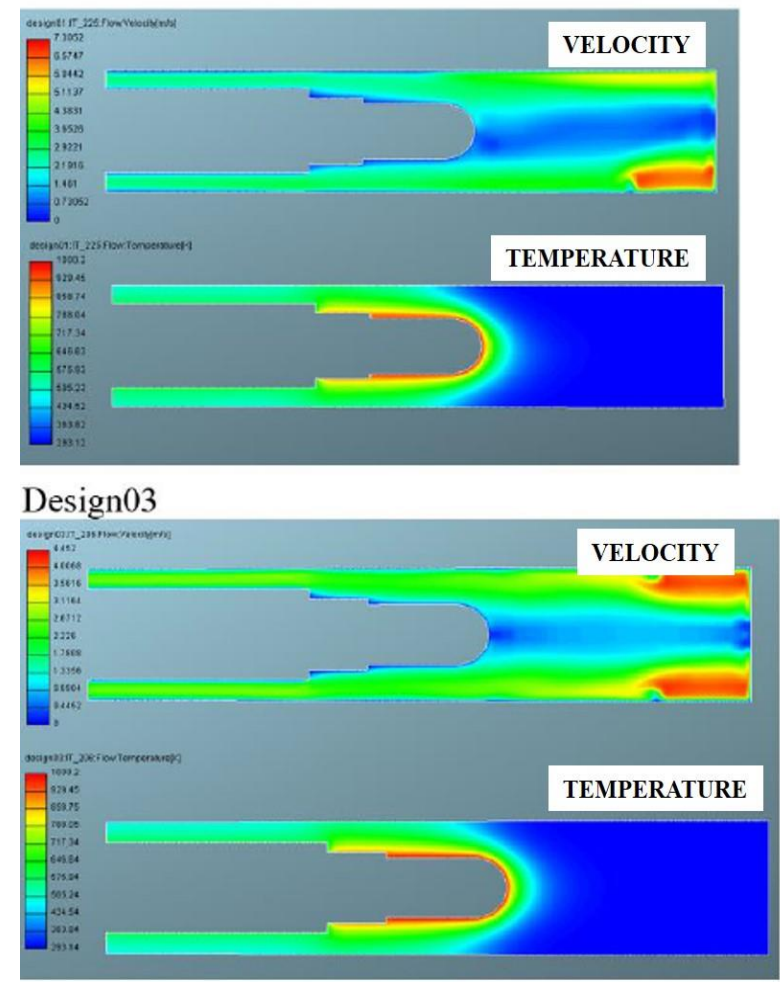

Design02
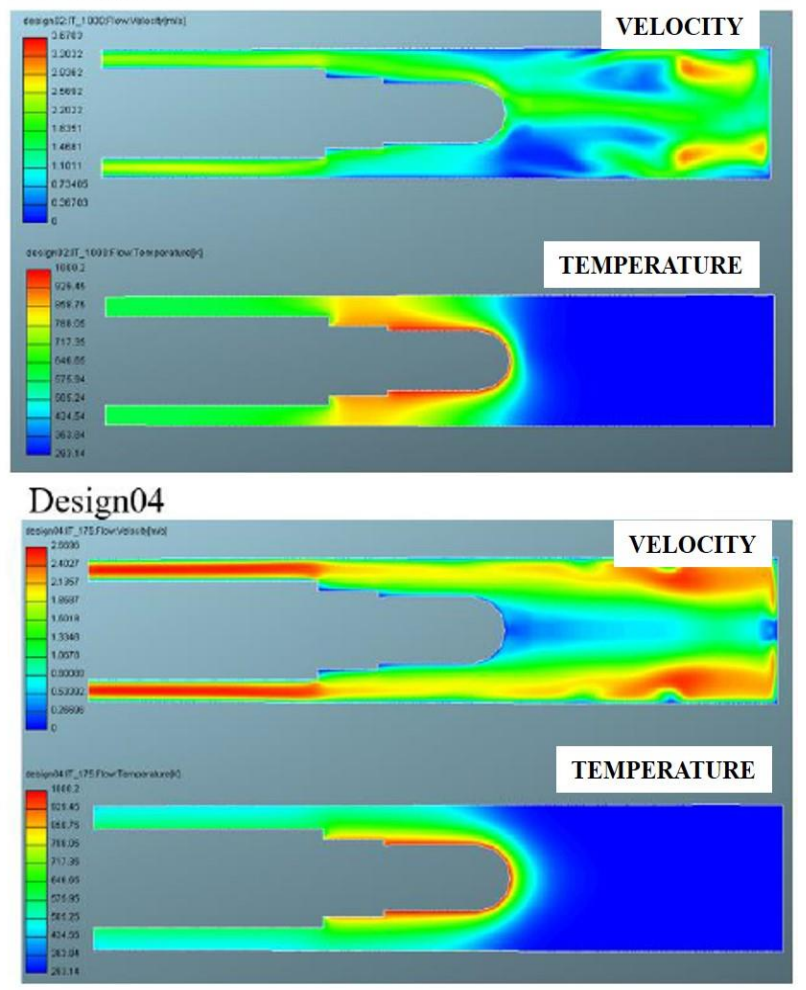

Fig. 10. Temperature distribution and velocity distribution for different inlet designs

Referring to Figure 10 above, single inlet (Design 1) shows much more higher gas velocity compared to double and 4 inlets. But Design 2, the velocity is below the non-optimized velocity. This can be explained by the design itself which makes the gas meet each other at the beginning and interrupted the laminar flow inside. This causes the flow to become more inconsistent and therefore much slower. However, for Design 1, 3 and 4 the difference of the velocity is quite big, but this does not show a very big difference in temperature distribution. Overall design show improvement for the temperature distribution around the glow plug with a higher velocity of gas except for Design 2 which has the highest temperature distribution with more lower gas velocity.

\section{Conclusions}

A 3D CFD model of hydrocarbon sensor chamber was built using AVL Software to investigate different parameter that influence the behaviour of the gas flow in laminar and turbulent flow that highly influence the ionization process and for the measurement of the ion current. From the steady state simulation, we can conclude that the optimum conditions for heating gas inside the chamber is when the inlet gas velocity is low and when the temperature of the glow plug is high. Validation 
between the experiment and simulation is also performed to compare whether the simulation data is good enough to be used. Finally, design of the hydrocarbon sensor is optimized to enhance the temperature distribution inside the chamber. This is performed by changing the inlet flow to create swirl flow of gas. From the result, the swirl flow shows higher temperature distribution. The swirl flow can be guided inside the chamber, then, it increases the temperature inside the chamber. Last but not least, with all parameters studied and design optimization carried out in this project will most likely to influence the ionization process of the gas in the chamber which effect the measurement of the ion current measurement.

\section{Acknowledgement}

The authors would like to acknowledge the financial support from Universiti Malaysia Pahang and Hochschule Karlsruhe-Technik und Wirtschaft (HsKA) under grant number RDU192703 and UIC191514.

\section{References}

[1] Pavlovic, Jelica, Alessandro Marotta, and Biagio Ciuffo. "CO2 emissions and energy demands of vehicles tested under the NEDC and the new WLTP type approval test procedures." Applied Energy 177 (2016): 661-670. https://doi.org/10.1016/i.apenergy.2016.05.110

[2] Varella, Roberto Aliandro, Barouch Giechaskiel, Luís Sousa, and Gonçalo Duarte. "Comparison of portable emissions measurement systems (PEMS) with laboratory grade equipment." Applied Sciences 8, no. 9 (2018): 1633. https://doi.org/10.3390/app8091633

[3] Giechaskiel, Barouch, Michael Clairotte, Victor Valverde-Morales, Pierre Bonnel, Zlatko Kregar, Vicente Franco, and Panagiota Dilara. "Framework for the assessment of PEMS (Portable Emissions Measurement Systems) uncertainty." Environmental Research 166 (2018): 251-260. https://doi.org/10.1016/i.envres.2018.06.012

[4] Kumar, Ashok, and K. A. Subramanian. "Control of greenhouse gas emissions (CO2, CH4 and N2O) of a biodiesel (B100) fueled automotive diesel engine using increased compression ratio." Applied Thermal Engineering 127 (2017): 95-105. https://doi.org/10.1016/i.applthermaleng.2017.08.015

[5] United States Environmental Protection Agency (EPA). "Inventory of U.S. Greenhouse Gas Emissions and Sinks." EPA.gov, April 9, 2021. https://www.epa.gov/ghgemissions/inventory-us-greenhouse-gas-emissions-and-sinks.

[6] Ostler, Simon. "Euro 6 Emissions Regulations - The Facts." PARKERS, April $29,2019$. https://www.parkers.co.uk/what-is/what-is-euro6-emissions-standards/.

[7] Garthe, Christopher, Rainer Ballik, Christa Hornreich, and W. Thiel. "HC measurements by means of flame ionization: Background and limits of low emission measurement." SAE Transactions (2003): 250-264. https://doi.org/10.4271/2003-01-0387

[8] BERU. "Ceramic Glow Plug." DRiV Automotiv Inc., 2009. https://www.beruparts.eu/parts/glow-plugs/ceramicglow-plug.html.

[9] Shuler, Kurt E., and Joseph Weber. "A Microwave Investigation of the Ionization of Hydrogen-Oxygen and Acetylene-Oxygen Flames." The Journal of Chemical Physics 22, no. 3 (1954): 491-502. https://doi.org/10.1063/1.1740095

[10] Papa, Louis J. "Gas chromatography-measuring exhaust hydrocarbons down to parts per billion." SAE Transactions (1968): 1797-1819. https://doi.org/10.4271/670494

[11] Bruner, Fabrizio. "Gas Chromatographic Environmental Analysis: Principles, Techniques, Instrumentation." Gas (1993).

[12] Saitzkoff, Andre, Raymond Reinmann, Thomas Berglind, and Magnus Glavmo. "An lonization Equilibrium Analysis of the Spark Plug as an lonization Sensor." SAE Transactions (1996): 452-462. https://doi.org/10.4271/960337

[13] Dewan, Edmond M. "Generalizations of the Saha equation." The Physics of Fluids 4, no. 6 (1961): $759-764$. https://doi.org/10.1063/1.1706395

[14] Dresser, M. J. "The Saha-Langmuir equation and its application." Journal of Applied Physics 39, no. 1 (1968): $338-$ 339. https://doi.org/10.1063/1.1655755

[15] Ebeling, W. "Equation of state and Saha equation of partially ionized plasmas." Physica 38, no. 3 (1968): $378-388$. https://doi.org/10.1016/0031-8914(68)90104-3 